\title{
Kontribusi Pemuda Muslim dalam Dunia Pendidikan Menuju Indonesia Emas Tahun 2045
}

\author{
${ }^{1}$ Nurul Khasanah, ${ }^{2}$ Rubini \\ ${ }^{12}$ STAI Masjid Syuhada Yogyakarta \\ E-mail: 1nurulk785@gmail.com, ${ }^{2}$ rubiniHr80@gmail.com
}

\begin{abstract}
Abstrak: Pemimpin bangsa Indonesia tahun 2045 adalah mereka yang saat ini sedang duduk di bangku sekolah, baik pendidikan usia dini, pendidikan dasar atau pendidikan menengah. Dalam dokumen Masterplan Percepatan dan Perluasan Pembangunan Ekonomi Indonesia (MP3EI) termuat harapan pada tahun 2025 Indonesia menjadi Negara yang mandiri, maju, adil dan makmur. Pemuda muslim Indonesia berperan penting dalam mewujudkan Indonesia emas 2045. Penelitian ini bertujuan untuk mengetahui kontribusi yang tepat bagi seorang pemuda muslim dalam mewujudkan Indonesia Emas pada tahun 2045, cara dan taktik apa yang akan digunakan dalam menyongsong 2045. Penelitian ini menggunakan metode Literature Review, yakni penggunaan metode yang sistematis, eksplisit dan reprodusibel untuk melakukan identifikasi, evaluasi dan sintesis terhadap karya-karya hasil penelitian dan hasil pemikiran yang sudah dihasilkan oleh para peneliti dan praktisi. Hasil kajian menunjukkan bahwa sosok pemuda muslim memiliki peran penting dalam mewujudkan Indonesia emas 2045. Pemuda diharapkan dapat membangun Indonesia yang maju, jaya dan bermartabat. Kontribusi dapat dilakukan dengan meningkatkan literasi, skill dan kompetensi. Pada sisi lain pemuda muslim diharapkan memiliki sikap kritis dan toleran serta meningkatkan kualitas literasi.
\end{abstract}

Kata Kunci: Kontribusi, Pemuda, Indonesia Emas 2045, Pendidikan

Abstract: The leaders of the Indonesian nation in 2045 are those who are currently in school, either in early childhood education, primary education or secondary education. The Master Plan for the Acceleration and Expansion of Indonesia's Economic Development (MP3EI) document contains the hope that by 2025 Indonesia will become an independent, advanced, just and prosperous country. Indonesian Muslim youth play an essential role in realizing a golden Indonesia 2045. This study aims to determine the appropriate contribution for Muslim youth in realizing a Golden Indonesia in 2045, what methods and tactics will be used in welcoming 2045. This study uses the Literature Review method, namely the use of systematic, explicit and reproducible methods to identify, evaluate and synthesize research works and ideas that researchers and practitioners have produced. The study results show that the figure of Muslim youth has a vital role in realizing a golden Indonesia 2045. Youth are expected to be able to build an advanced, prosperous and dignified Indonesia. Contributions can be made by improving literacy, skills and competencies. On the other hand, Muslim youth are expected to have a critical and tolerant attitude and improve the quality of literacy.

Keywords: Contribution, Youth, Indonesia Gold 2045, Education 


\section{PENDAHULUAN}

Perkembangan zaman semakin pesat, polemic yang dihadapi pun begitu bertubi-tubi. Tantangan untuk lebih kreatif, inovasi, pengembangan karya, dan kontribusi dalam dunia pendidikan kerap dilakukan. Berbagai macam strategi telah menjadi rencana untuk merevolusikan pendidikan di Indonesia menjadi lebih baik. Pemuda sebagai generasi penerus bangsa menjadi suatu pemahaman yang tidak baru lagi. Perubahan-perubahan besar yang ada di dunia pendidikan tidak terlepas dari peran pemuda yang sangat berkontribusi secara signifikan, dari segi fakta maupun realita. Dilihat dari riwayat perjuangan bangsa Indonesia terdahulu pemuda menjadi garda terdepn dalam proses pembaharuan, perjuangan dan pembangunan bangsa Indonesia.

Menilik lintasan sejarah Sumpah Pemuda 1928, pemuda memiliki andil besar dalam menentukan arah tujuan suatu bangsa. Generasi muda adalah kunci utama terwujudnya Indonesia emas. kontribusi pemuda sangat dibutuhkan dalam proses transformasi Indonesia maju, maka dari itu sebagai generasi penerus bangsa, kita harus bangkit dengan menggandeng seluruh lapisan pemuda untuk bersatu mengolah celah visi Indonesia emas. Melalui dunia pendidikan, bisa merubah sudut pandang satu langkah lebih maju.

Dalam islam, peran pemuda muslim dalam pendidikan lebih rumit lagi cakupannya, seperti memikirkan bagaimana menjadi Indonesia emas melalui elemenelemen islam, dan mengaitkannya dalam kaidah islam. Dalam falsafah islam, seperti yang diungkapkan oleh abu hanifah tujuan Pendidikan islam akan mempengaruhi kaidah, metode dan pendekatan pendidikan yang akan digunakan dalam proses pembelajaran. Pandangan abu hanifah mengenai tujuan pendidikan terlihat jelas dalam ilmu dan amal. Ia menegaskan bahwa, suatu perbuatan hendaknya menurut panduan (petunjuk) ilmu, sebagaimana anggota badan menuruti panduan penglihatan. Sesungguhnya ilmu yang disertai perbuatan sedikit ialah yang lebih bermanfaat, dibanding kebodohan yang disertai perbuatan banyak. Ilmu pengetahuan itu seperti bekal yang sedikit tetapi jelas manfaatnya bagi seorang musafir, sedangkan kebodohan itu seperti bekal yang banyak namun tidak diketahui manfaatnya oleh seorang musafir.

Polemic yang selalu disuguhkan dalam akhir - akhir ini yaitu pemuda yang hilang peran nya dalam dunia pndidikan. Sudah sering terjadi, problem pemuda yang mengabaikan tugas dan kewajibannya sendiri dalam persatuan untuk mewujudkan visi indonesia maju. Kerap telihat, hal - hal kecil seperti, pemuda yang malas belajar, malas membaca ataupun diskusi dan susah untuk berbaur sehingga mindset yang terbangun pun sedikit.. Hal tersebut menjadi penghambat indonesia maju, karena pemuda yang menjadi cikal bakal agent of change saja menyepelekan hal tersebut. Dengan demikian, apabila masalah di atas tidak segera diatasi, akan munculnya masalah-masalah baru. Yang mungkin lebih besar peluang nya dalam mengikis 
semangat para pemuda indonesia. Berdasarkan permasalahan tersebut, maka perlu diterapkan strategi yang lebih menarik dan memacu pemuda untuk bergerak membangun indonesia emas pada tahun 2045.

\section{METODE PENELITIAN}

Penelitian ini menggunakan metode Literature Review. Literature Review merupakan istilah yang digunakan tertuju pada metodologi penelitian atau riset tertentu dan suatu pengembangan yang dilakukan untuk mengumpulkan serta mengevaluasi suatu penelitian yang terkait pada fokus tersebut.

Literature Review dilakukan dalam penelitian untuk memperoleh beberapa tujuan diantaranya adalah mengidentifikasi, mengkaji, mengevaluasi dan menafsirkan penelitian yang tersedia dengan tema dan fenomena yang menarik, dengan pertanyaan tertentu yang sesuai. Metode ini juga sering digunakan untuk penentuan agenda riset, sebagai bagian dari disertasi atau tesis, serta bagian yang melengkapi pengajuan hibah riset. 1

\section{HASIL DAN PEMBAHASAN}

\section{Generasi Emas Indonesia}

Generasi emas merupakan dambaan bangsa Indonesia setelah menjalani masa kemerdekaan selama tepat satu abad. Diharapkannya bibitbibit berkualitas yang mampu bersaing secara sehat di kancah nasional hingga internasional. Keberadaannya tersebar di berbagai pelosok negeri, dari Sabang hingga Merauke. Hal ini membuat adanya suatu persebaran terkait keberadaanya. Generasi emas diharapkan terbentuk pada tahun 2045, momentum paling penting dalam sejarah peradaban bangsa Indonesia. Harapan besarnya, pada tahun 2045 Indonesia akan diisi oleh generasi yang memiliki usia produktif dalam jumlah yang mayoritas diantara usia penduduk sekarang (Abi, 2017), (Soter, 2019). Menurut Manullang (2013), generasi yang diperkirakan memegang peranan penting di tahun 2045 terutama adalah peserta didik yang saat ini sedang duduk di SD, SMP dan SLTA, termasuk juga mereka yang sedang duduk di perguruan tinggi. ${ }^{2}$

Generasi emas ini sebagai generasi penerus bangsa yang akan menentukan masa depan dan integritas bangsa Indonesia. Generasi emas yang terdiri atas generasi muda yang penuh optimis dan gairah untuk mempunyai sikap dan pola pikir yang berlandaskan maju. Generasi yang

${ }^{1}$ E Triandini, dkk, "Metode Systematic Literature Review untuk Identifikasi Platform dan Metode Pengembangan Sistem Informasi di Indonesia”, (Denpasar : Indonesian Journal of Information Systems, 2019), hlm. 63

2 Ainin Amini, dkk, "Sebuah Kegiatan Menginspirasi Siswa Menuju Generasi Emas Indonesia", (Universitas Mataram : Jurnal Pemberdayaan Masyarakat Berkarakter, 2020), hlm. 11 
bermoral kokoh dengan visi ke depan yang cemerlang. Generasi emas ini juga diharapkan memiliki kompetensi yang memadai karakter yang kokoh kecerdasan yang tinggi, dan kompetitif.

\section{Pendidikan Menuju 2045}

Generasi emas 2045 adalah kekuatan utama membangun bangsa indonesia menjadi bangsa yang besar, maju, jaya dan bermartabat. Mengelola generasi emas akan menjadi tantangan terbesar bangsa indonesia.. untuk mewujudkannya bukannlah pekerjaan mudah, seperti membalikkan telapak tangan. Oleh karenanya, demi mewujudkan harapan dan impian tersebut, semua elemen masyarakat harus berperan aktif dalam meraih cita-cita tersebut melalui pendidikan karakter. Karakter menentukan kualitas moral dan arah dari setiap generasi muda dalam mengambil keputusan dan tingkah laku. Karakter juga merupakan bagian integral yang harus dibangun, agar generasi muda sebagai harapan dan penerus yang akan menentukan masa depan bangsa harus memiliki sikap dan pola pikir yang berlandaskan moral yang kokoh dan benar dalam upaya membangun bangsa.

Dalam menciptakan pendidikan berkualitas ada beberapa pembenahan yang harus dilakukan untuk merealisasikan berbagai ide yang muncul.

Pertama adalah perbaikan mutu tenaga pendidik. Tenaga pendidik inilah yang nantinya akan menjadi penentu terciptanya kesuksesan pendidikan di Indonesia. Guru yang bermutu menjadi faktor utama dalam mewujudkan pendidikan yang berkualitas. Banyaknya isu-isu miring terkait kinerja guru menyebabkan kinerja guru Indonesia seolah dipertanyakan sehingga saat ini guru dituntut untuk bekerja secara profesional, bukan hanya sekedar melepas kewajiban semata. Kesadaran guru untuk membantu pemerintah dalam mewujudkan cita-cita Bangsa Indonesia seperti yang tertuang dalam Pembukaan UUD 1945, "mencerdaskan kehidupan bangsa", sangat dibutuhkan karena menjadi suatu kewajiban bagi guru dan tenaga pendidik.

Kedua adalah kurikulum yang diterapkan. Seperti yang telah dijelaskan sebelumnya bahwa kurikulum lainnya untuk menjadi tonggak pergerakan kemajuan bangsa disektor pendidikan. yang diterapkan haruslah dipersiapkan dengan sebaik mungkin sebelum diberlakukan secara nasional agar tidak terjadi inefisiensi terhadap keuangan negara. Selain itu kurikulum yang diterapkan sedapat mungkin berdampak positif bagi pembentukan karakter generasi muda Indonesia.

Ketiga adalah perbaikan sarana dan prasarana yang menunjang berlangsungnya proses pendidikan. Misalnya perbaikan gedung sekolah, pelengkapan fasilitas laboraturium sekolah, pengadaan buku-buku dan 
sumber literatur lain, pengadaan alat-alat canggih berbasis teknologi, penciptaan lingkungan dan suasana belajar yang nyaman dan kondusif. Langkah nyata adalah pengadaan berbagai macam beassiswa untuk siswa berprestasi ataupun siswa yang terkendala keadaan ekonomi keluarga sehingga tidak ada lagi alasan bagi generasi muda Indonesia untuk tidak bersekolah. Adanya beasiswa ini diharapkan untuk generasi muda agar berlomba-lomba meningkatkan kualitas dirinya terutama dalam hal pendidikan. Selain itu, kemudahan untuk mengenyam pendidikan ini juga diharapkan menjadi langkah pasti bagi terwujudnya generasi emas Indonesia.

\section{Kontribusi Yang Dilakukan Menuju Generasi Emas Tahun 2045}

Untuk mempersiapkan generasi emas Indonesia 2045, penting bagi dunia pendidikan melakukan perubahan pola pikir. Pendidikan tidak sekadar dimaknai dengan transfer akademik (keilmuan) saja, melainkan dilengkapi dengan karakter. Keseimbangan akademik dan karakter inilah yang perlu disiapkan sejak sekarang. Hal itu disampaikan Rektor IKIP PGRI Semarang Dr Muhdi SH MHum dalam diskusi ilmiah "Menyiapkan Pendidikan Generasi Emas Anak Bangsa untuk Mencapai Indonesia Emas" yang diselenggarakan Universitas Muria Kudus (UMK) di Auditorium Kampus, Senin (8/4). Pemerintah selalu menuntut guru untuk bisa lebih kreatif, inovatif dan inspiratif dalam mendesain kegiatan pembelajaran yang bermutu untuk menyongsong generasi emas Indonesia. Jika memang guru menjadi kunci utama, seharusnya pemerintah meletakkan kekuasaan penuh terhadap guru untuk menyusun kurikulum serta mengevaluasi. Untuk mencapai generasi emas Indonesia maka diperlukan juga Usaha pemuda dalam berkontribusi meningkatkan mutu pendidikan di Indonesia seperti:

a. Pendidikan yang melatih kesadaran kritis

Sikap yang kritis dan toleran, akan merangsang tumbuhnya kepekaan sosial dan rasa keadilan. Oleh karena itu diharapkan bisa mengatasi kemelut sosial, budaya, politik dan ekonomi bangsa ini.

b. Pemberdayaan Guru

Berhubung Guru dituntut lebih kreatif, inovatif, terampil, berani berinisiatif serta memiliki sikap politik yang jelas. sebaiknya, pemerintah memberdayakan guru dengan program-program latihan sehingga mereka mampu mengembangkan model-model pengajaran secara variatif. ${ }^{3}$

c. Mewujudkan Pendidikan Bermutu

Perwujudan proses pendidikan bermutu dipengaruhi oleh kinerja pendidik dan tenaga kependidikan, kualitas dan kuantitas sarana dan

3 Regina Ade Darman, "Mempersiapkan Generasi Emas Indonesia Tahun 2045 Melalui Pendidikan Berkualitas", (Sumbar : Jurnal Edik Informatika, 2017), hlm. 84-85. 
prasarana pendidikan,kualitas pengelolaan pendidikan,ketersediaan dana pendidikan, dan sistem penilaian pendidikan yang valid,obyektif, dan akuntabel.

Pendidikan nasional bermutu diarahkan untuk pengembangan potensi peserta didik agar menjadi manusia yang beriman dan bertakwa kepada Tuhan Yang Maha Esa, berakhlak mulia, sehat, berilmu, cakap, kreatif, mandiri, dan menjadi warga negara yang demokratis serta bertanggungjawab. Dengan berkembangnya potensi peserta didik, maka akan dapat mewujudkan generasi emas Indonesia sebagai generasi penerus bangsa yang berkarakter, cerdas dan kompetitif, sehingga akan meningkatkan kesejahteraan, keharkatan dan kemartabatan bangsa dan negara Indonesia. 4

d. Meningkatkan Minat Baca

Menteri Pendidikan, Kebudayaan, dan Ristek (Mendikbud-Ristek) Nadiem Makarim mengungkapkan penyebab pendidikan Indonesia tertinggal dari negara lain karena sektor pendidikan kita tidak boleh mengambil risiko. Padahal, Indonesia, menurut Menteri pendidikan, memiliki banyak potensi keberagaman. Sayangnya, anak-anak yang awalnya dituntut berinovasi dan berkreasi, dan ada kebijakan yang mendukung hal tersebut, justru dianggap berisiko sehingga inovasi yang sudah terbangun menjadi terhambat bahkan stagnan. Hal tersebut juga menjadi faktor menurunnya minat baca para peserta didik, yang mengakibatkan pendidikan indonesia tertinggal. dalam dunia literasi Indonesia menempati peringkat ke-62 dari 70 negara, seperti dalam survei yang dilakukan Program for International Student Assessment (PISA) yang dirilis Organization for Economic Co-operation and Development (OECD) pada 2019.

Untuk itu, peningkatan minat baca sangat dibutuhkan dalam proses perwujudan indonesia emas 2045. Dimulai dari hal terkecil seperti, membaca hal yang disukai. Sebagai contoh membaca novel, mungkin novel bukan merupakan bacaan yang secara kasat mata dapat menambah wawasan, namun sebetulnya novel mempunyai makna tersendiri dalam mengungkapkan kebermanfaatan nya. Dari kita membaca novel, kita bisa memperkaya tata Bahasa, meningkatkan memori, menggugah empati, dan lebih open minded atau pikiran menjadi terbuka. Dari situlah lambat laun minat baca akan semakin bertambah dan dapat beralih dri novel menjadi buku, jurnal ataupun artikel.

${ }^{4}$ Prof. Dr. Mungin Eddy Wibowo, M.Pd.,Kons, "Menyiapkan Bangkitnya Generasi Emas Indonesia.", (Universitas Negeri Semarang) 


\section{KESIMPULAN}

Pemuda muslim menjadi tonggak utama dalam mewujudkan visi Indonesia emas pada tahun 2045. Indonesia emas 2045 merupakan dambaan masyarakat Indonesia memperingati 100 tahun kemerdekaan Indonesia. Generasi emas 2045 kekuatan utama membangun bangsa indonesia menjadi bangsa yang besar, maju, jaya dan bermartabat. Untuk itu, perlu adanya sebuah dorongan dan partisipasi pemuda menuju indonesia emas. Adapun kontriibusi yang perlu dilakukan pemuda ialah :

a. Pendidikan yang melatih kesadaran kritis. Sikap yang kritis dan toleran, akan merangsang tumbuhnya kepekaan sosial dan rasa keadilan. Oleh karena itu diharapkan bisa mengatasi kemelut sosial, budaya, politik dan ekonomi bangsa ini.

b. Pemberdayaan Guru Berhubung Guru dituntut lebih kreatif, inovatif, terampil, berani berinisiatif serta memiliki sikap politik yang jelas. sebaiknya, pemerintah memberdayakan guru dengan program-program latihan sehingga mereka mampu mengembangkan model-model pengajaran secara variatif. 5

c. Mewujudkan Pendidikan Bermutu. Mewujudkan proses pendidikan bermutu dipengaruhi oleh kinerja pendidik dan tenaga kependidikan, kualitas dan kuantitas sarana dan prasarana pendidikan,kualitas pengelolaan pendidikan,ketersediaan dana pendidikan, dan sistem penilaian pendidikan yang valid,obyektif, dan akuntabel. Pendidikan nasional bermutu diarahkan untuk pengembangan potensi peserta didik agar menjadi manusia yang beriman dan bertakwa kepada Tuhan Yang Maha Esa, berakhlak mulia, sehat, berilmu, cakap, kreatif, mandiri, dan menjadi warga negara yang demokratis serta bertanggungjawab. Dengan berkembangnya potensi peserta didik, maka akan dapat mewujudkan generasi emas Indonesia sebagai generasi penerus bangsa yang berkarakter, cerdas dan kompetitif, sehingga akan meningkatkan kesejahteraan, keharkatan dan kemartabatan bangsa dan negara Indonesia. 6

d. Meningkatkan Minat Baca. Menteri Pendidikan, Kebudayaan, dan Ristek (Mendikbud-Ristek) Nadiem Makarim mengungkapkan penyebab pendidikan Indonesia tertinggal dari negara lain karena sektor pendidikan kita tidak boleh mengambil risiko. Padahal, Indonesia, menurut Menteri pendidikan, memiliki banyak potensi keberagaman. Sayangnya, anak-anak yang awalnya dituntut berinovasi dan berkreasi, dan ada kebijakan yang mendukung hal tersebut, justru dianggap berisiko sehingga inovasi yang sudah terbangun menjadi terhambat bahkan stagnan. Hal tersebut juga menjadi factor menurunnya minat baca para peserta didik, yang mengakibatkan pendidikan indonesia tertinggal. dalam dunia literasi Indonesia menempati peringkat ke-62 dari 70 negara, seperti dalam survei yang dilakukan Program for International Student Assessment (PISA) yang

${ }^{5}$ Regina Ade Darman, op. cit., hlm. 84

${ }^{6}$ Prof. Dr. Mungin Eddy Wibowo, M.Pd.Kons, op. cit. 
dirilis Organization for Economic Co-operation and Development (OECD) pada 2019. Untuk itu, peningkatan minat baca sangat dibutuhkan dalam proses perwujudan indonesia emas 2045. Dimulai dari hal terkecil seperti, membaca hal yang disukai. Sebagai contoh membaca novel, mungkin novel bukan merupakan bacaan yang secara kasat mata dapat menambah wawasan, namun sebetulnya novel mempunyai makna tersendiri dalam mengungkapkan kebermanfaatan nya. Dari kita membaca novel, kita bisa memperkaya tata Bahasa, meningkatkan memori, menggugah empati, dan lebih open minded atau pikiran menjadi terbuka. Dari situlah lambat laun minat baca akan semakin bertambah dan dapat beralih dri novel menjadi buku, jurnal ataupun artikel.

\section{DAFTAR PUSTAKA}

Ainin Amini, dkk. 2020. Sebuah Kegiatan Menginspirasi Siswa Menuju Generasi Emas Indonesia.Universitas Mataram: Jurnal Pemberdayaan Masyarakat Berkarakter.

E Triandini, dkk. 2019. Metode Systematic Literature Review untuk Identifikasi Platform dan Metode Pengembangan Sistem Informasi di Indonesia. Denpasar: Indonesian Journal of Information Systems

Prof. Dr. Mungin Eddy Wibowo, M.Pd.,Kons. Menyiapkan Bangkitnya Generasi Emas Indonesia. Universitas Negeri Semarang

Regina Ade Darman. 2017. Mempersiapkan Generasi Emas Indonesia Tahun 2045 Melalui Pendidikan Berkualitas. Sumbar : Jurnal Edik Informatika. 